"Additional binding sites for anionic phospholipids and $\mathrm{Ca} 2+$ ions in the crystal structures of complexes of the $\mathrm{C} 2$ domain of protein kinase $\mathrm{C} \alpha$." Ochoa, W.F., Corbalán-García, S., Eritja, R., Rodríguez-Alfaro, J.A., Gómez-Fernández, J.C., Fita, I., Verdaguer, N. J. Mol Biol., 320(2), 277-291 (2002).

doi: $10.1016 / \mathrm{S} 0022-2836(02) 00464-3$

\title{
Additional Binding Sites for Anionic Phospholipids and Calcium lons in the Crystal Structures of Complexes of the C2 Domain of Protein Kinase $\mathrm{C} \alpha$
}

\section{Wendy F. Ochoa ${ }^{1}$, Senena Corbalán-Garcia ${ }^{2}$, Ramon Eritja ${ }^{1}$, José A. Rodríguez-Alfaro ${ }^{2}$, Juan C. Gómez-Fernández ${ }^{2}$, Ignacio Fita $^{1}$ and Nuria Verdaguer ${ }^{1 *}$}

${ }^{1}$ Instituto de Biología Molecular de Barcelona (CSIC), Jordi Girona Salgado 18-26, E08034 Barcelona, Spain

2Departamento de Bioquímica y Biología Molecular (A) Facultad de Veterinaria

Universidad de Murcia Apartado de Correos 4021 E-30080 Murcia, Spain

*Corresponding author. E-mail address of the corresponding author: nvmcri@ibmb.csic.es

\begin{abstract}
The $\mathrm{C} 2$ domain of protein kinase $\mathrm{C} \alpha(\mathrm{PKC} \alpha)$ corresponds to the regulatory sequence motif, found in a large variety of membrane trafficking and signal transduction proteins, that mediates the recruitment of proteins by phospholipid membranes. In the $\mathrm{PKC} \alpha$ isoenzyme, the $\mathrm{Ca}^{2+}$-dependent binding to membranes is highly specific to $1,2-s n$-phosphatidyl-L-serine. Intrinsic $\mathrm{Ca}^{2+}$ binding tends to be of low affinity and non-cooperative, while phospholipid membranes enhance the overall affinity of $\mathrm{Ca}^{2+}$ and convert it into cooperative binding. The crystal structure of a ternary complex of the PKC $\alpha-\mathrm{C} 2$ domain showed the binding of two calcium ions and of one 1,2-dicaproyl-sn-phosphatidyl-L-serine (DCPS) molecule that was coordinated directly to one of the calcium ions. The structures of the $\mathrm{C} 2$ domain of PKC $\alpha$ crystallised in the presence of $\mathrm{Ca}^{2+}$ with either 1,2- diacetyl-sn-phosphatidyl-L-serine (DAPS) or 1,2-dicaproyl-sn-phosphatidic acid (DCPA) have now been determined and refined at $1.9 \AA$ and at $2.0 \AA$ , respectively. DAPS, a phospholipid with short hydrocarbon chains, was expected to facilitate the accommodation of the phospholipid ligand inside the $\mathrm{Ca}^{2+}$-binding pocket. DCPA, with a phosphatidic acid (PA) head group, was used to investigate the preference for phospholipids with phosphatidyl-Lserine (PS) head groups. The two structures determined show the presence of an additional binding site for anionic phospholipids in the vicinity of the conserved lysine-rich cluster. Site-directed mutagenesis, on the lysine residues from this cluster that interact directly with the phospholipid, revealed a substantial decrease in C2 domain binding to vesicles when concentrations of either PS or PA were increased in the absence of $\mathrm{Ca}^{2+}$. In the complex of the $\mathrm{C} 2$ domain with DAPS a third $\mathrm{Ca}^{2+}$, which binds an extra phosphate group, was identified in the calcium-binding regions (CBRs). The interplay between calcium ions and phosphate groups or phospholipid molecules in the $\mathrm{C} 2$ domain of $\mathrm{PKC} \alpha$ is supported by the specificity and spatial organisation of the binding sites in the domain and by the variable occupancies of
\end{abstract}


ligands found in the different crystal structures. Implications for PKC $\alpha$ activity of these structural results, in particular at the level of the binding affinity of the $\mathrm{C} 2$ domain to membranes, are discussed.

Keywords: C2 domain; protein kinase C; phosphatidic acid; phosphatidylserine; X-ray structures

Abbreviations used: PK, protein kinase; DAG, diacyglycerol; DCPS, 1,2-dicaproyl-snphosphatidyl-L-serine; DAPS, 1,2-diacetyl-sn-phosphatidyl-L-serine; DCPA, 1,2-dicaproyl-snphosphatidic acid; PA, phosphatidic acid; PS, phosphatidyl-L-serine; CBR, calcium-binding region.

\section{Introduction}

Protein kinase $\mathrm{C}(\mathrm{PKC})$ is a family of phospholipid- dependent serine/threonine kinases that includes at least 11 different mammalian isoforms. PKCs can be classified into three groups, according to their structure and cofactor regulation: the first group includes the classical isoforms $(\alpha, \beta \mathrm{I}, \beta \mathrm{II}$, and $\gamma)$ that are activated by diacyglycerol (DAG) and cooperatively by calcium and acidic phospholipids. The second group consists of novel PKCs $(\delta, \lambda, \eta$ and $v)$, which are also activated by acidic phospholipids and DAG, though their function is not regulated by $\mathrm{Ca}^{2+}$. The third group comprises the atypical PKC isoforms $(\zeta, \lambda$ and $\mu$ ), whose regulation has not been clearly established, although their activity is stimulated by phosphatidylserine (PS). [1,2]

In conventional PKC isotypes, binding sites for their activators are located in the amino-terminal regulatory domain [3] composed of three functionally different elements: (i) a self-inhibiting pseudosubstrate sequence at the amino terminus, which, upon activation is thought to be released from the active site of the enzyme. (ii) The $\mathrm{C} 1$ domain that contains two cysteine-rich modules (C1A and C1B) and binds DAG and phorbol esters. (iii) The C2 domain, which is located at the carboxy end of the regulatory region and is responsible for binding to $\mathrm{Ca}^{2+}$ and to anionic phospholipids.

Table 1. Data and model refinement statistics.

\begin{tabular}{|l|c|c|}
\hline & $\mathrm{C} 2-\mathrm{Ca}^{2+}$-DCPA & C2- $\mathrm{Ca}^{2+}$-DAPS \\
\hline Space group & $P 3_{2} 21$ & $a=b=58.15, c=89.93$ \\
\hline Cell parameters $(\AA)$ & $a=b=57.99, c=90.97$ & 1.9 \\
\hline Resolution range $(\AA)$ & 2.0 & 14,327 \\
\hline & & 7233 \\
\hline No. reflections Total & 14,545 & $8.9(34.2)$ \\
\hline No. reflections Unique & 7503 & $99(98)$ \\
\hline $\mathrm{R}_{\text {merge }}(\%)^{\mathrm{a}}$ & $9.6(35.6)$ & 24.7 \\
\hline Completeness $(\%)$ & $99.8(100)$ & 28.5 \\
\hline Average $(1 / \sigma)$ & & 50 \\
\hline$R$-factor $(\%)$ & 25.4 & \\
\hline$R_{\text {free }}(\%)$ & 28.7 & \\
\hline Solvent content $(\%, \mathrm{v} / \mathrm{v})$ & 50 & \\
\hline
\end{tabular}




\begin{tabular}{|l|c|c|}
\hline No.protein residues & 135 & 135 \\
\hline No. solvent molecules & 50 & 78 \\
\hline Average thermal factor $\left(\AA^{2}\right)$ & 38.1 & \\
\hline Protein & 42.2 & $25.2 / 22.2 / 28.7$ \\
\hline Water & $34.9 / 33.7 / 59.2$ & $60.4 / 66.1$ \\
\hline $\mathrm{Ca}^{2+}(1 / 2 / 3)$ & $35.3 / 75.5$ & 0.007 \\
\hline Phospholipids & & 2.0 \\
\hline Geometry deviation & 0.019 & \\
\hline Bond distance $(\AA)$ & 1.2 & \\
\hline Bond angle (deg.) & & \\
\hline
\end{tabular}

${ }^{\mathrm{a}}$ Last resolution shell in parentheses.

${ }^{a}$ Temperature factors obtained when the three sites, particularly that corresponding to $\mathrm{Ca} 3$, are assumed to be fully occupied by calcium ions.

${ }^{a}$ The first value corresponds to the phospholipid found into the calcium-binding pocket and the second value corresponds to the phospholipid found in the lysine-rich cluster site

In the PKC $\alpha$ isoenzyme, the $\mathrm{Ca}^{2+}$-dependent binding to membranes is highly specific for $1,2-s n$ phosphatidyl-L-serine. [4-7] Homologues of the PKC $\alpha \mathrm{C} 2$ domain correspond to a regulatory sequence motif of about 130 amino acid residues that is found in a large variety of membrane trafficking and signal transduction proteins, in which the domain mediates the protein recruitment by phospholipid membranes. $[8,9]$ All C2 domains are composed of a stable $\beta$-sandwich with flexible loops on top and at the bottom. The $\mathrm{Ca}^{2+}$-binding regions (CBRs), in the $\mathrm{C} 2$ domains that bind $\mathrm{Ca}^{2+}$, are formed mainly by five aspartate side-chains, located at the flexible top loops, that serve as bidentated ligands for two or three calcium ions.[10 - 15] Intrinsic $\mathrm{Ca}^{2+}$ binding tends to be of low affinity and non-cooperative, probably because the bound calcium ions contain empty coordination sites.[16,17] Phospholipid membranes increase overall $\mathrm{Ca}^{2+}$ affinity and convert $\mathrm{Ca}^{2+}$ binding into cooperative.[11,13,18 - 20] It is likely that phospholipids achieve this effect by providing additional coordination sites for the incompletely bound $\mathrm{Ca}^{2+} \cdot$.21] The structure of the ternary complex of the PKC $\alpha-\mathrm{C} 2$ domain with $\mathrm{Ca}^{2+}$ and 1,2-dicaproyl- snphosphatidyl-L-serine (DCPS) determined recently,[15] showed one of the $\mathrm{Ca}^{2+}$ coordinated simultaneously by the CBRs and by the head group of a DCPS molecule, which interacts also with some of the positively charged residues surrounding the calcium-binding pocket. Fatty acyl chains from the DCPS molecule, though partially exposed to the solvent, made hydrophobic contacts with residues from CBR3.

The crystal structures of the $\mathrm{C} 2$ domain of $\mathrm{PKCa}$, crystallised in the presence of $\mathrm{Ca}^{2+}$ and of either 1,2-diacetyl-sn-phosphatidyl-L-serine (DAPS) or 1,2-dicaproyl-sn-phosphatidic acid (DCPA), are explained in this study. DAPS, a phospholipid with shorter hydrocarbon chains than DCPS, was chosen in order to facilitate the accommodation of the phospholipid inside the $\mathrm{Ca}^{2+}$-binding pocket. Comparisons between the ternary complexes with either DCPA or DCPS were expected to provide information on the specificity of PKC $\alpha$ for the PS head group. 

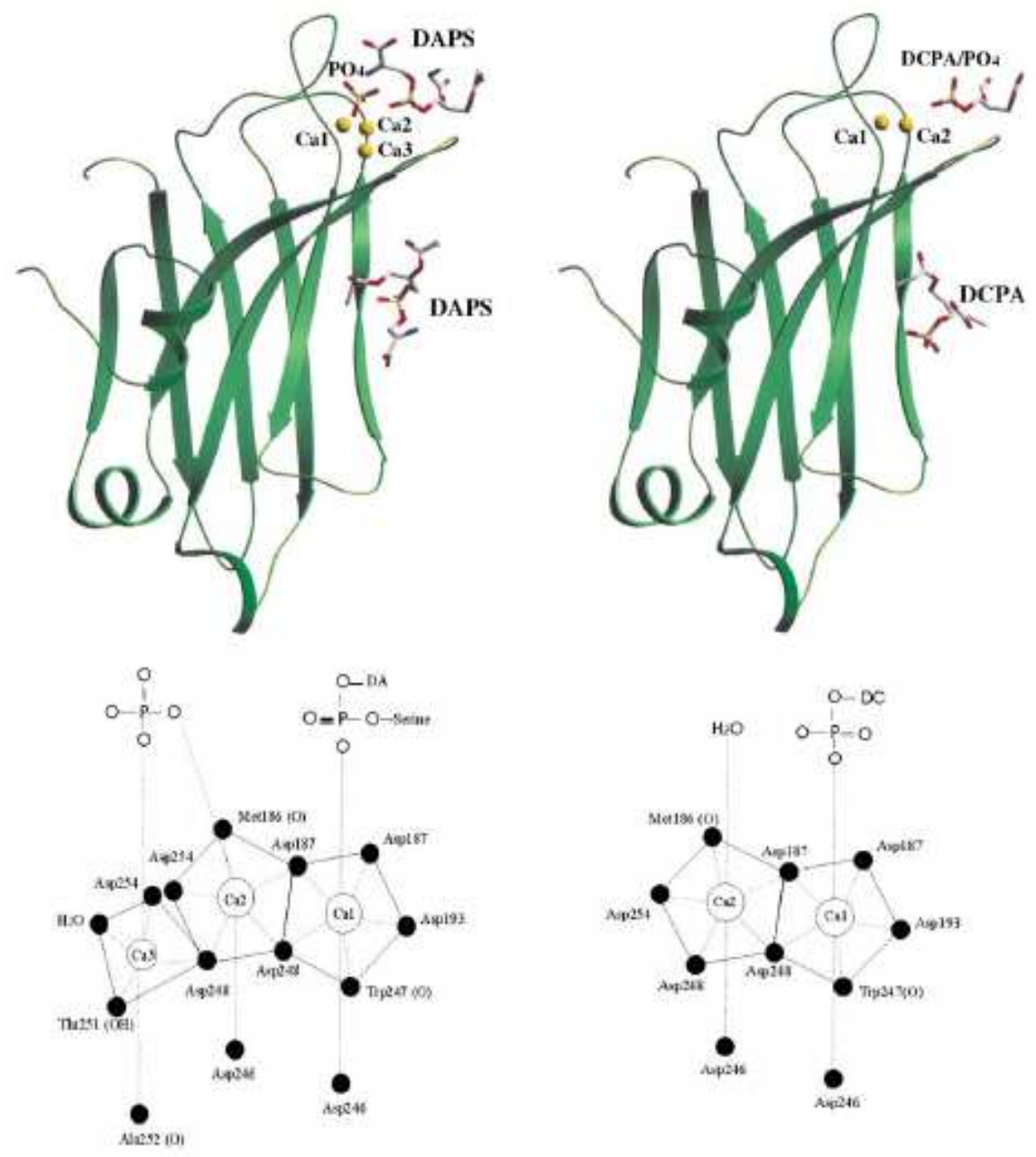

(a)

(b)

Figure 1. Overall structures of the $\mathrm{C} 2$ domain of PKC $\alpha$ bound to (a) DAPS and (b) DCPA. $\beta$-Strands are depicted as arrows. The calcium ions located at the top of the domain, in the calcium-binding regions (CBRs), are represented as yellow balls. The phosphate group and phospholipid molecules are depicted as filled sticks. For the DCPA molecule found in the calcium-binding region, only the phosphoryl moiety was clearly defined (see the text). Coordination schemes of the calcium ions in the two structures are shown in the lower part of the Figure. The scheme of the DCPA complex assumes that only Ca1 and Ca2 are present, though the partial occupancy of $\mathrm{Ca} 3$ is possible, as discussed extensively in the text (see also Figure 2).

\section{Results}

\section{Overall structure and calcium-binding sites}

The PKC $\alpha-C 2$ domain produced as a recombinant fragment, including residues from His 155 to Gly293, was crystallised in the presence of $\mathrm{Ca}^{2+}$ and the short-chain phospholipids DAPS and DCPA.

Diffraction data sets were measured at $100 \mathrm{~K}$, using synchrotron radiation, to resolutions of $1.9 \AA$ and 2.0 $\AA$ for the DAPS and DCPA crystal complexes, respectively (Table 1). Coordinates from the isolated 
PKC $\alpha-C 2$ domain [15] were used as the searching model to determine the structure of the two complexes by molecular replacement (see Materials and Methods). In both crystals, the quality of the final electron density maps allowed the accurate positioning of most residues and side-chains. Only densities of the highly exposed $N$-terminal residues His 155 to Lys 158 and of side chains from Lys197 and Arg252 were poorly defined in both structures. The root-mean-square deviation (rmsd) of the superimposition of the 134 equivalent $\mathrm{Ca}$ atoms from the $\mathrm{C} 2$ domains in the crystal structures of the two complexes is $0.18 \AA$, which reflects the fact that these structures are essentially identical in conformation (Figure 1). The structures of the $\mathrm{C} 2$ domain in both complexes are also closely related to the conformations determined previously, for the isolated domain and when complexed with DCPS, [15] which gave rmsd values of only about $0.2 \AA$ (Table 2$)$.

The final model for the PKC $\alpha-C 2-\mathrm{Ca}^{2+}$-DAPS complex includes a $\mathrm{C} 2$ domain, 78 solvent molecules, three calcium ions and one phosphate ion, and two DAPS molecules (Table 1). Two of the calcium ions, equivalent to the central calcium sites II and III according to the convention of Essen et al.,[12] coincided with $\mathrm{Ca} 1$ and $\mathrm{Ca} 2$, as defined previously in the structures of the isolated $\mathrm{PKC} \alpha-\mathrm{C} 2$ domain and in the structure of the PKC $\alpha-C 2-\mathrm{Ca}^{2+}-$ DCPS complex.[15] The third $\mathrm{Ca}^{2+}$ (indicated as $\mathrm{Ca} 3$ in Figures 1 and 2) was at a location equivalent to site IV, as defined by Essen et al.,[12] and had a strong peak of density in its vicinity that was interpreted as a phosphate ion, probably coming from the solution employed in crystallization (Figure 2). In the crystal structures of the isolated C2 domain and of its complex with DCPS, the site corresponding to Ca3 is occupied by one water molecule. [15] The first DAPS molecule was found inside the $\mathrm{Ca}^{2+}$-binding pocket connected to $\mathrm{Ca} 1$ in a location equivalent to that in the DCPS complex (Figure 1).[15] Density corresponding to this DAPS molecule was strong only for the phosphoserine moiety, having a maximum in the position of the phosphate group. Well-defined electron density for a second DAPS molecule was found near the conserved lysine-rich cluster, which includes lysine residues at positions 197, 199, 209, 211 and 213 from strands ( $\beta 3$ and ( $\beta 4$ (Figure 3).

Figure 2. Stereo-views of the PKC $\alpha$ C2 domain corresponding to site IV, [14] as found in the structures of the ternary complexes with (a) DCPS[15], (b) DAPS or (c) DCPA. Only protein residues that define the coordination sphere of $\mathrm{Ca} 3$ in the DAPS complex are depicted, though Asp248 has been omitted for clarity (see the coordination schemes in Figure 1) and the side-chain of Arg252, disordered in the three complexes, is not represented. $\mathrm{Ca} 3$ is represented as a green ball and water molecules in its vicinity in red. The phosphate ion coordinating with both $\mathrm{Ca} 3$ and $\mathrm{Ca} 2$ is shown in the DAPS complex $2 F_{o}-F_{c}$ electron density maps (SigmaA weighted), contoured at $1.0 \mathrm{~s}$, are shown with a chicken-box representation for the (b) DAPS and (c) DCPA structures. Weakness of the electron density (c) in the DCPA complex corresponding to the location occupied by $\mathrm{Ca} 3$ in (b) the DAPS complex suggests the partial occupancy of calcium in this site in the DCPA structure (see the text and Table 2). 
(a)

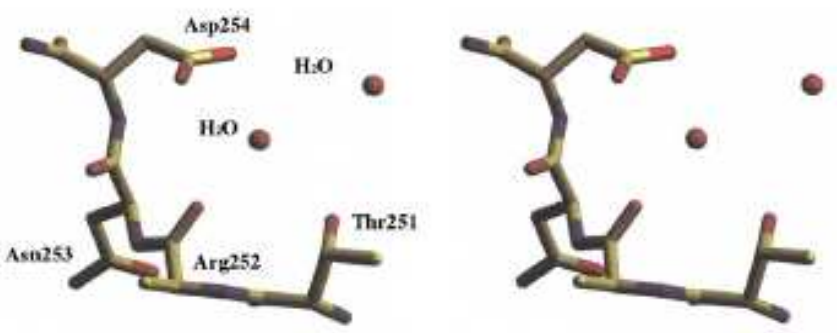

(b)

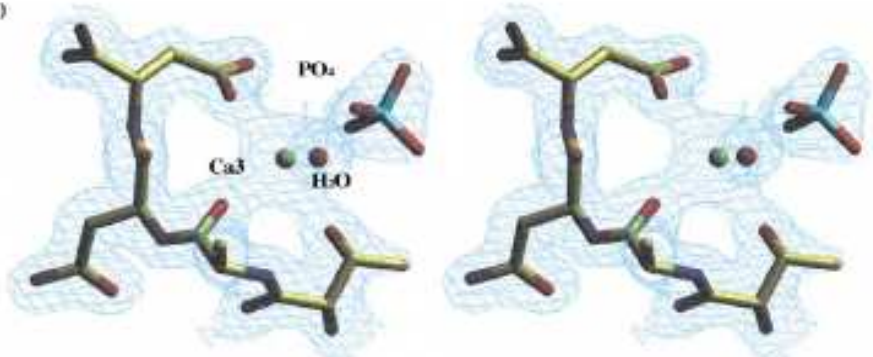

(c)

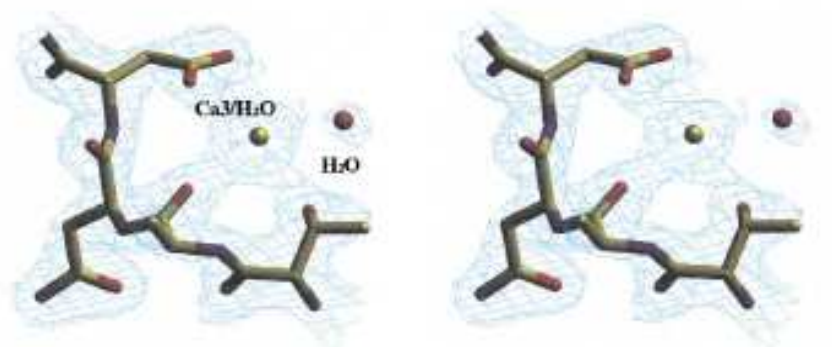

The final structure of the PKC $\alpha-\mathrm{C} 2-\mathrm{Ca}^{2+}-\mathrm{DCPA}$ ternary complex includes a $\mathrm{C} 2$ domain, 50 solvent molecules, two or three (see below) calcium ions and two DCPA molecules (Table 1). In this complex, electron density confirmed the presence of the $\mathrm{Ca}^{2+}$ corresponding to $\mathrm{Ca} 1$ and $\mathrm{Ca} 2$, while density, in the location corresponding to $\mathrm{Ca} 3$ in the DAPS complex, was weak, which could be interpreted either as a $\mathrm{Ca}^{2+}$ with low occupancy $\left(B_{\text {factor }}=59.2 \AA^{2}\right)$ or as a well-defined water molecule $\left(B_{\text {factor }}=29.2 \AA^{2}\right.$; Figure 2). Also absent from the DCPA complex was density, equivalent to the density seen close to $\mathrm{Ca} 3$ in the DAPS complex, that could correspond to a phosphate molecule (Figure 2). The two DCPA molecules found in the DCPA complex were in the same locations as the two phospholipids in the DAPS complex: (i) at the $\mathrm{Ca}^{2+}$-binding site in the vicinity of $\mathrm{Ca} 1$; and (ii) near the conserved lysinerich cluster (Figure 3). However, electron density for the DCPA molecule in the $\mathrm{Ca}^{2+}$ pocket, even poorer than for the corresponding molecule in the DAPS complex, was well defined only for the phosphoryl moiety, weakening fast for the glycerol and acyl chains. Electron density for the second DCPA molecule near the lysine-rich cluster was clear for the phosphoryl and glycerol head groups, and for the first carbon atoms of the acyl chains (Figure 3). Ca1 and Ca2, in both the DAPS and the DCPA complexes, were heptacoordinated, while $\mathrm{Ca} 3$, in the DAPS complex, was hexacoordinated (Figure 1). In all cases, the $\mathrm{Ca}^{2+}$-ligand coordination distances ran from 2.3 to $2.6 \AA$ A . Protein $\mathrm{Ca}^{2+}$ ligands corresponded to the sidechains of the five conserved aspartic residues (at positions 187, 193, 246, 248 and 254) and to the main chain of residues Met186 and Trp247, which provided six of the seven oxygen atoms that coordinate Ca1 and $\mathrm{Ca} 2$, as found in the PKC $\alpha$-C2-DCPS structure.[15] The seventh ligand of Ca1 was an oxygen atom 
from the phosphoryl group of either the DAPS or DCPA molecule in the DAPS or DCPA complexes, respectively. Four of the six $\mathrm{Ca} 3$ ligands were protein oxygen atoms from the main chain of $\operatorname{Arg} 252$ and from the side-chains of Asp248, Thr251 and Asp254 (Figure 2). The fifth and sixth ligands of Ca3 were, respectively, a water molecule and the extra phosphate ion, which interacted also with Ca2 (Figure 1).

Table 2. Summary of calcium ions and phosphate and phospholipid molecules found in the four PKC $\alpha$ C2 domain.

\begin{tabular}{|c|c|c|c|c|}
\hline $\mathrm{PKC} \alpha-\mathrm{C} 2$ domain structures & $\mathrm{Ca}^{2+}$ & $\mathrm{Ca}^{2+-} \mathrm{DCPS}^{\mathrm{a}}$ & $\mathrm{Ca}^{2+-} \mathrm{DCPA}^{\mathrm{b}}$ & $\mathrm{Ca}^{2+-} \mathrm{DAPS}^{b}$ \\
\hline Number $\mathrm{Ca}^{2+-}$ & 2 & $2^{\mathrm{c}}$ & $2^{d}$ & 3 \\
\hline $\begin{array}{l}\text { Ligands in the calcium- } \\
\text { binding region }\end{array}$ & $\begin{array}{l}\mathrm{Ca} 1-\mathrm{PO}_{4}, \\
\mathrm{Ca} 2-\mathrm{H}_{2} \mathrm{O}\end{array}$ & $\begin{array}{lr}\text { Ca1-DCPS } & (0.5 \\
\text { occupancy }), & \text { Ca2- } \\
\mathrm{H}_{2} \mathrm{O} & \\
\end{array}$ & $\begin{array}{ll}\text { Ca1-DCPA } & \text { e, Ca2- } \\
\mathrm{H}_{2} \mathrm{O} & \end{array}$ & $\begin{array}{l}\text { DAPS }^{f}, \quad \text { Ca2- }-\mathrm{PO}_{4-} \\
\text { Ca3 }\end{array}$ \\
\hline $\begin{array}{l}\text { Ligands in the lysine-rich } \\
\text { cluster region }\end{array}$ & $\mathrm{PO}_{4}$ (poor) & $\mathrm{PO}_{4}$ (poor) & $\begin{array}{l}\text { DCPA (acyl chains } \\
\text { are only visible in } \\
\text { part) }\end{array}$ & $\begin{array}{l}\text { DAPS (whole } \\
\text { molecule) }\end{array}$ \\
\hline Resolution $(\AA)$ & 2.4 & 2.6 & 2.0 & 1.9 \\
\hline $\begin{array}{l}\text { rmsd on the binary } \\
\text { complex }\end{array}$ & 0.00 & 0.25 & 0.22 & 0.24 \\
\hline
\end{tabular}

${ }^{\mathrm{a}}$ Verdaguer et al. [15]

b This study

${ }^{c}$ One water molecule could be another $\mathrm{Ca}^{2+}$ with very low occupancy

${ }^{\mathrm{d}}$ One water molecule is likely to be another $\mathrm{Ca}^{2+}$ with low occupancy

${ }^{\mathrm{e}}$ Only the phosphoryl group from this DCPA molecule is well defined with an assigned occupancy of 1.0 (see the text)

${ }^{\mathrm{f}}$ Both the phosphoryl and the seryl groups from this DAPS molecule are well defined with assigned occupancies of 1.0 (see the text) 
(a)
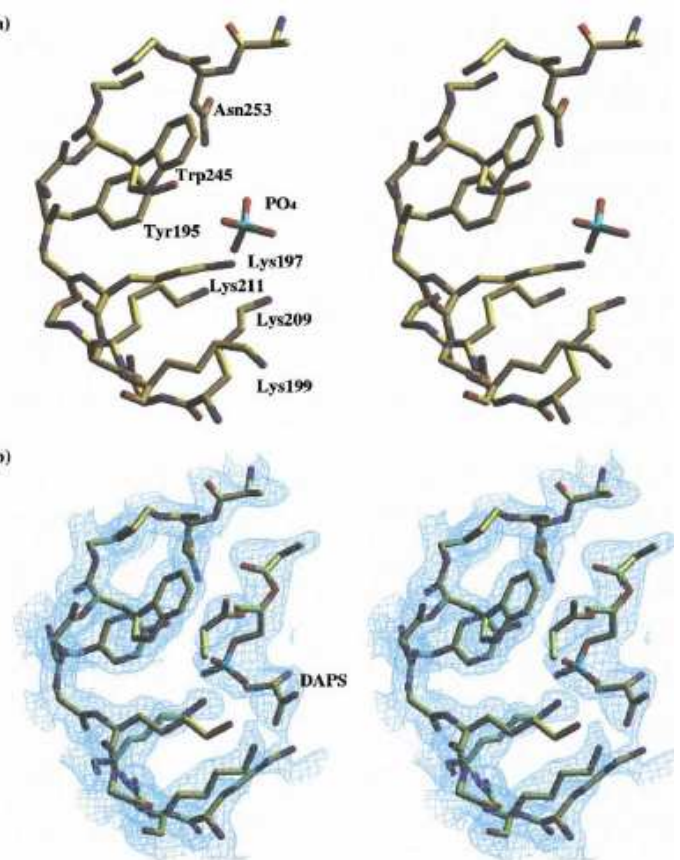

(c)
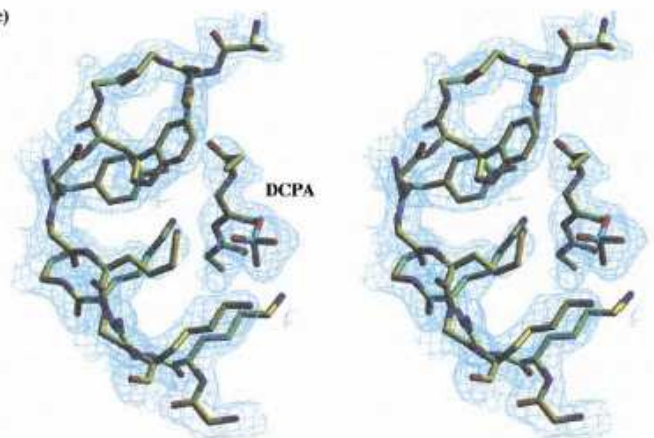

Figure 3. Stereo-views of the $\mathrm{PKC} \alpha \mathrm{C} 2$ domain corresponding to the lysine-rich cluster regions as found in the structures of the ternary complexes with (a) DCPS,15 (b) DAPS or (c) DCPA. $2 F_{o}-F_{c}$ (SigmaA weighted) electron density maps, contoured at $1.0 \mathrm{\sigma}$, are shown with a chicken-box representation for the (b) DAPS and (c) DCPA structures. For clarity, only residues directly involved in the interaction with the phospholipids in the DCPS complex are shown (see Figure 4). Phosphate and phospholipid ligands are represented with the thickest sticks. 

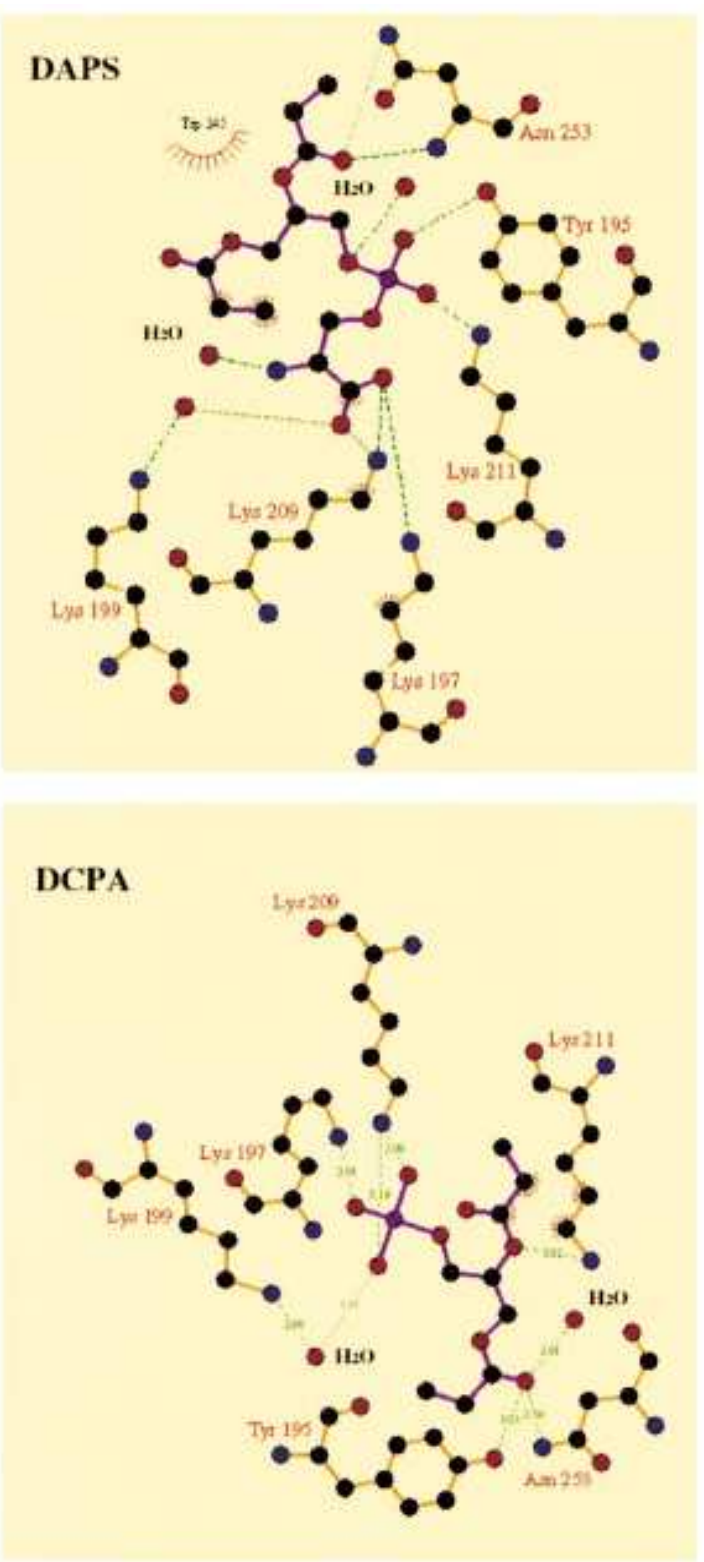

Figure 4. Plot of interactions, drawn with the LIGPLOT program, [41] between the PKC $\alpha-\mathrm{C} 2$ domain with (a) the DAPS and (b) the DCPA molecules found in the lysine-rich cluster in the corresponding structures (see the text and Figure 3).

\section{Interactions of DAPS and DCPA}

The phosphoglycerol backbone of the phospholipid pocket had similar interactions in the DAPS and the DCPA complexes. One of the phosphoryl oxygen atoms from the phospholipid was coordinated with $\mathrm{Ca} 1$, while the glycerol moiety was hydrogen-bonded to the guanidinium groups of arginine residues 216 and 249. In the DAPS complex, the phospholipid serine head group interacted also with the C2 domain residues Pro188 and Asn189 in CBR1. These specific interactions between the serine residue from the phospholipid and the C2 domain, necessarily absent from the DCPA complex, could contribute to the enhanced affinity of $\mathrm{PKC} \alpha$ for PS-containing membranes. Interactions equivalent to those 
described for the DAPS complex were found in the structure of the PKC $\alpha$-C2 domain with DCPS. [15] However, in the DCPS complex, the fatty acyl chains from the phospholipid had hydrophobic contacts with residues from CBR3. These interactions, which might contribute to binding, were not present in the DAPS complex, because of the short hydrocarbon chains of DAPS.

A second phospholipid ligand was found, as indicated before, near the conserved lysine-rich cluster in both the DAPS and the DCPA complexes (Figures 3 and 4). The clustering of the exposed lysine side-chains, from the $\beta 3$ and $\beta 4$ strands, endowed the concave surface of the $\mathrm{C} 2$ domain with a strong positive electrostatic character suited to interact with anionic charges. The head group from the DAPS molecule found near the lysine-rich cluster had a conformation more extended than that in the two PS lipid molecules, DAPS and DCPS, found in the calcium-binding pocket. [15] The DAPS terminal carboxylate group, from the serine moiety, made a short and strong salt-bridge with Lys209 (Figures 3 and 4). The Lys197 side-chain, though not well defined, pointed towards the carboxylate group, probably also interacting ionically. Finally, the carboxylate group interacted with a well-defined water molecule that is bound to Lys199 (Figures 3 and 4). In turn, the DAPS phosphate group had an ionic interaction with the side-chain of Lys211 and made a hydrogen bond with the phenol oxygen atom of Tyr195 (Figures 3 and 4). The C2 domain residues Trp245 and Asn253 contacted the DAPS glycerol and acyl chains (Figures 3 and 4). The short fatty acyl chains of the DAPS molecule appear to point towards the solvent (Figure 5), which could explain the difficulties in filling this site with a phospholipid with longer acyl chains, such as DCPS. [15] However, DCPA, despite having fatty acyl chains the same length as DCPS, is able to bind near the lysinerich cluster and the polar head of a DCPA molecule was clearly defined at this site in the DCPA complex (Figure 3). Fatty acyl chains of this DCPA molecule departed from the surface of the $\mathrm{C} 2$ domain, becoming fully exposed to the solvent and disordered except for the first few (one to three) carbon atoms (Figures 3 and 4). The phosphoryl group of this DCPA molecule was located in the position occupied by the terminal carboxylate group in the DAPS complex and had almost identical interactions: (i) a strong salt-bridge with Lys209; (ii) a hydrogen bond with a well-defined water molecule that, in turn, is bound to the side chain of Lys 199; and (iii) a second probable salt bridge with Lys197, which was oriented towards the phosphoryl group but was partially disordered, as was the case in the DAPS complex (Figures 3 and 4). C2 domain residues Tyr 195, Lys211 and Asn253 had a number of different interactions with the DCPA molecule (Figure 4).

The proximity, both in sequence and in the spatial organisation, of the residues defining the $\mathrm{Ca} 3$ binding site (particularly Asp248, Thr251 and the main chain of Arg252) to some of the residues from the lysine-rich cluster region interacting with the phospholipids, particularly Asn253, should be noted (Figure 1). 


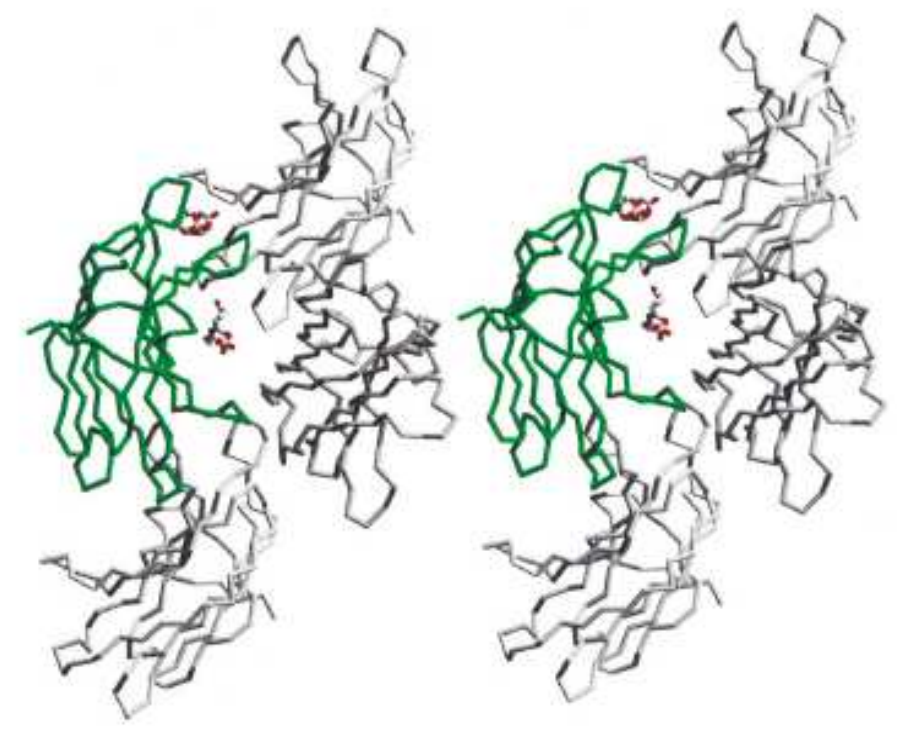

Figure 5. Stereo-view of the packing interactions in the vicinity of the two phospholipid- binding sites found in the structure of the ternary complex PKC $\alpha-C 2-\mathrm{Ca}^{2+}-\mathrm{DAPS}$. The reference molecule is depicted in green and the phospholipid ligands in atom colour code. The three closest neighbour molecules are presented in grey.

\section{Site-directed mutagenesis analysis}

The structures of the PKC $\alpha-C 2$ domain with DAPS and DCPA determined in the present study prompted us to re-investigate the lysine-rich cluster by site-directed mutagenesis. Two constructs were engineered fused to glutathione-S-transferase (GST): (i) in the first construct, wild-type lysine residues 209 and 211 were replaced by alanine (GST-C2 $\alpha-K 209$ A/K211A); and (ii) in the second construct, lysine residue 197 was changed to alanine (GST-C2 $\alpha-K 197 \mathrm{~A} / \mathrm{K} 209 \mathrm{~A} / \mathrm{K} 211 \mathrm{~A}$ ). Binding assays to vesicles with increasing percentages of either PS or PA were performed for both constructs in the presence of $200 \mathrm{mM}$ $\mathrm{CaCl} 2$ and in the absence of calcium (Figure 6).

When calcium was present, the maximal binding activity and the affinity of the two constructs had almost the same behaviour as that of the wildtype protein (Figure 6(a) and (c)). Instead, when calcium was absent, important differences were observed (Figure 6(b) and (d)). For vesicles containing PS, the maximal binding activity of the two constructs reached only about $30 \%$ with respect to the wild-type protein. For vesicles containing PA, the maximal binding activity of the constructs was about 50\% compared to that of the wild-type protein. Note also that in the absence of calcium the affinity of the wildtype protein to bind to PA-containing vesicles is higher than that exhibited for PS-containing vesicles (Figure 6(a) and (c)). 

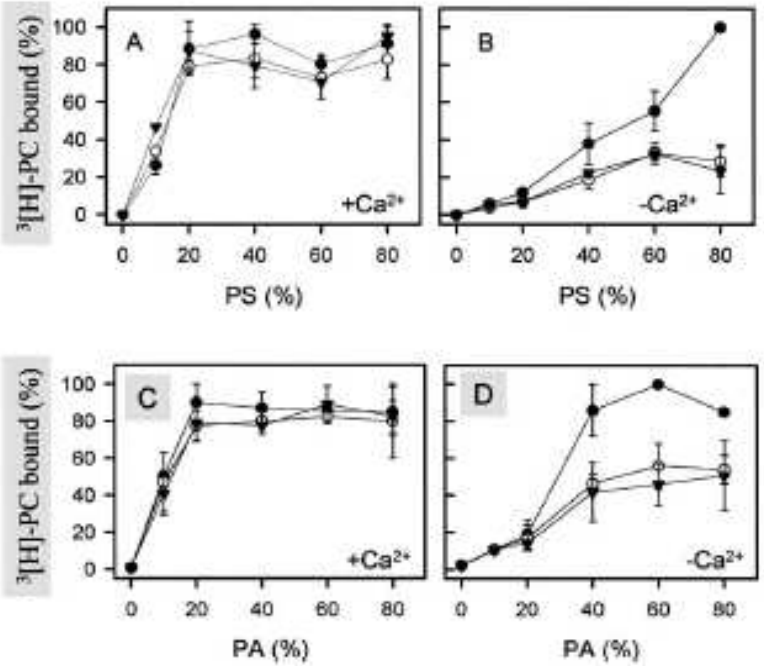

Figure 6. PS dependence of phospholipid binding to the GST-C $2 \alpha$ domain (X), GST-C2 $\alpha-\mathrm{K} 209 \mathrm{~A} /$ K211A (W) and GST-C2 $\alpha-K 197 \mathrm{~A} / \mathrm{K} 209 \mathrm{~A} / \mathrm{K} 211 \mathrm{~A}$ (P) (a) in the presence of $200 \mathrm{mM} \mathrm{CaCl}_{2}$ and (b) in its absence. Binding of ${ }^{3} \mathrm{H}$-labelled PC/PS small unilamellar vesicles to the different constructs was analysed by increasing the concentration of PS in the vesicles. Similar studies were made of the PA dependence of phospholipid binding to the GST-C2 $\alpha$ domain (X), GSTC2 $\alpha-K 209 A / K 211 \mathrm{~A}$ (W) and GSTC2 $\alpha-\mathrm{K} 197 \mathrm{~A} / \mathrm{K} 209 \mathrm{~A} / \mathrm{K} 211 \mathrm{~A}$ (P) (c) in the presence of $200 \mathrm{mM} \mathrm{CaCl} 2$ and (d) in its absence. For $\mathrm{PA}$, the binding of ${ }^{3} \mathrm{H}$-labeled PC/PA small unilamellar vesicles to the different constructs was analysed by increasing the concentration of PA in the vesicles. In all cases, GST was used as a background control, with error bars indicating the standard error for triplicate determinations.

\section{Discussion}

The present study was initiated to complement the information obtained with the crystal structures of the isolated $\mathrm{C} 2$ domain of PKCa and of the ternary complex of the domain with $\mathrm{Ca}^{2+}$ and DCPS. [15] The structure of the ternary complex showed, bound to the protein, two calcium ions, one phosphate group in the lysine-rich cluster region, and one DCPS molecule in the calciumbinding pocket with only 50\% occupancy (Table 2). The direct coordination of Ca1 with the head group of the bound DCPS molecule provided an apparently straightforward explanation of the relationships between the two ligands. In addition, specific interactions of the serine moiety of the phospholipid explained, at least in part, the preference of PKCa for phosphatidyl-L-serine lipids. Mutational analysis confirmed that some residues, seen in direct contact with the DCPS molecule, play a critical role in PS-dependent activation and membrane translocation of PKC $\alpha .[22,23]$ Furthermore, hydrophobic contacts between the DCPS fatty acyl chains and residues from CBR3 suggested the penetration of this region inside the anionic membranes, which confirmed a number of previous observations. [24,25] However, despite these hydrophobic contacts, solvent accessibility and positional disorder increased along the fatty acyl chains, which might interfere with complex formation and crystal packing leading to the low occupancy of the bound phospholipid found in the ternary complex with DCPS (Figure 5). [15] Therefore, it was hypothesized that a PS lipid with shorter hydrocarbon chains than DCPS, such as DAPS, might facilitate the accommodation of the phospholipid inside the calcium-binding pocket, increasing occupancy and 
improving the definition. Differences between complexes of the $\mathrm{C} 2$ domain and different phospholipids with and without the serine group, such as DCPS and DCPA, were expected to provide clues to the preference of PKC $\alpha$ for PS-containing membranes.

Confirming expectations, the DAPS molecule found inside the calcium-binding pocket, that corresponds well in location and interactions to the only DCPS molecule found in the DCPS complex, had higher occupancy in the DAPS complex (Table 2). In the DCPA complex, the absence of the serine headgroup and of its specific interactions seems to reduce, as anticipated, the affinity for the binding site inside the calcium pocket and only the phosphoryl moiety from the DCPA molecule appears well defined.

Despite the findings, described above, that confirmed the initial hypothesis, the results obtained from the crystal structures of DAPS or DCPA had important novel features. Both the DAPS and the DCPA complexes showed clearly a second molecule of phospholipid bound at a new site of the C2 domain. The additional binding site was located not inside the calcium-binding pocket but in the vicinity of the conserved lysine-rich cluster in the concave surface of the $\mathrm{C} 2$ domain (Figures 1 and 3). In the

complex with DAPS, a third $\mathrm{Ca}^{2+}$ was present, coordinated with an extra phosphate group, in the top region of the $\mathrm{C} 2$ domain (Figures 1 and 2). In the complex with DCPA, the third $\mathrm{Ca}^{2+}$ might be present with partial occupancy (Figure 2).

\section{Calcium-binding site. The third calcium ion}

Why is the third calcium ion absent from the DCPS complex and possible present, but only with partial occupancy, in the DCPA complex? The binding of the third calcium ion seems to correlate with the presence of phospholipids in the lysine-rich site. The interplay between both ligands is suggested also by the spatial proximity of the two binding sites (Figure 1). However, as no significant structural rearrangement of the $\mathrm{C} 2$ domain was detected between the DAPS, DCPS and DCPA complexes, no important cooperative effects are expected due to the binding in the lysine-rich cluster site. [26] The high occupancy of the third calcium ion in the DAPS complex besides the presence of the phospholipid in the lysine-rich cluster site could reflect some contribution from PS bound in the calcium pocket. The presence of the phosphate group interacting with $\mathrm{Ca} 3$ indicates that a third binding site for head groups of anionic phospholipids could be available in the $\mathrm{C} 2$ domain when the third calcium ion is bound. The direct involvement of the side-chain from residue Thr251 in the coordination of the third calcium ion could contribute to the dramatic effects observed by mutational analysis on this residue [23] that was reported to interact also with the phospholipid in the DCPS complex. [15] In any event, the third calcium ion is likely to bind with extremely low affinity in solution but might become trapped physiologically in a ternary C2 domain-membrane complex similar to what has been proposed to happen in PKC $\beta$. [27]

\section{The lysine-rich cluster binding site}

Possible functions of the conserved and characteristic lysine-rich cluster from the $\mathrm{C} 2$ domain of classical PKCs had been investigated, in particular by mutational analysis, with no clear consequences for enzymatic activity. [23,28 - 30] However, in the crystal structure of the PKC $\alpha-\mathrm{C} 2$ domain with DCPS, 
one phosphate group was identified in the lysinerich cluster region. [15] When co-crystallised with ophospho-L-serine, the structure of the $\mathrm{C} 2$ domain of $\mathrm{PKC} \beta$, which contains a lysine-rich cluster in the molecular region equivalent to that in the $\mathrm{PKC} \alpha-\mathrm{C} 2$ domain, showed extra electron density near the cluster that was interpreted as corresponding to the o-phospho-L-serine ligand. [14] The site-directed mutagenesis studies presented in this work indicate that replacements of some residues from the lysinerich cluster introduce, in fact, significant membrane-binding differences in the modified proteins with respect to the wild-type, but only in the absence of calcium (Figure 6). Hence, membrane binding by the C2 domain is dominated by the presence of calcium, though the lysine-rich cluster appears to have a minor, calcium-independent, contribution that becomes clearly detectable only when calcium is absent.

Phospholipid binding at the lysine-rich cluster appears to be dominated by electrostatic interactions, while hydrophobic contacts, likely to be required for membrane penetration, are mostly excluded. This electrostatic character suggests that anionic membranes should interact avidly with the lysine-rich cluster. Why then does the lysine-rich cluster have only a minor contribution in the binding of the isolated C2 domain to anionic membranes? Despite being at the surface of the protein, the lysine-rich cluster appears somehow inaccessible to interactions with the membrane. A simple explanation of this reduced accessibility is provided by the concave shape of the $\mathrm{C} 2$ domain. For the lysine-rich cluster to reach the surface of a membrane, some other parts of the $\mathrm{C} 2$ domain have to be in contact with the membrane. These other regions are limited to the CBR3 and to the calcium-binding pocket in the docking models, requiring minimal penetration of the C2 domain into the membrane. [15] Therefore, in the absence of calcium, the attractive interaction towards anionic membranes of the lysine-rich cluster is expected to be counterbalanced by the repulsive interactions of other parts of the protein, particularly by the negatively charged residues from the calcium binding pocket. In the presence of calcium, the behaviour is reversed, and binding to membranes would be dominated by the interactions mediated by the calcium ions. However, even in the presence of calcium, the lysine-rich cluster would contribute to determination of the positioning of the enzyme with respect to the membrane and to an increase in the stability of the protein-membrane docking to the levels required by the functioning of the enzyme at different stages.

Some of the structural features of the C2 domain can show its full meaning only in the context of the different conformations that the several parts of a PKC $\alpha$ molecule can adopt. Residue Asp55 from the $\mathrm{C} 1 \mathrm{~A}$ domain has been shown to be dramatically important for the activation of $\mathrm{PKC} \alpha$ and those authors suggested this residue to be involved in the tethering of the $\mathrm{C} 1 \mathrm{~A}$ domain to another part of PKC $\alpha$ that keeps it in an inactive conformation at the resting state. [31] Modelling supports the attractive possibility of docking the $\mathrm{C} 1 \mathrm{~A}$ domain into the concave face of the $\mathrm{C} 2$ domain by placing the Asp55 sidechain near the lysine-rich cluster, while the hydrophobic surfaces corresponding to the DAG binding site, in the $\mathrm{C} 1 \mathrm{~A}$ domain, and to the $\mathrm{CBR} 3$ region, in the $\mathrm{C} 2$ domain, contact with each other (Figure 7). These interdomain interactions would explain the inaccessibility of the DAG binding site in the C1A domain [32] and possibly of the lysine-rich cluster site in the $\mathrm{C} 2$ domain, while maintaining the conformation of $\mathrm{PKC} \alpha$ in the resting state. Calcium, when present, would trigger the binding of the $\mathrm{C} 2$ domain onto the anionic membranes leading to penetration of CBR3 into the membrane, [15] which would be facilitated by the removal of the $\mathrm{C} 1 \mathrm{~A}$ domain if bound to the concave surface of the $\mathrm{C} 2$ domain (see below). 
Separation of domains C1A and C2 would, in turn, allow the DAG binding pocket and the lysine-rich cluster to become accessible and to experience further interactions. Work with the full-length PKC $\alpha$ to test these possibilities is being started.

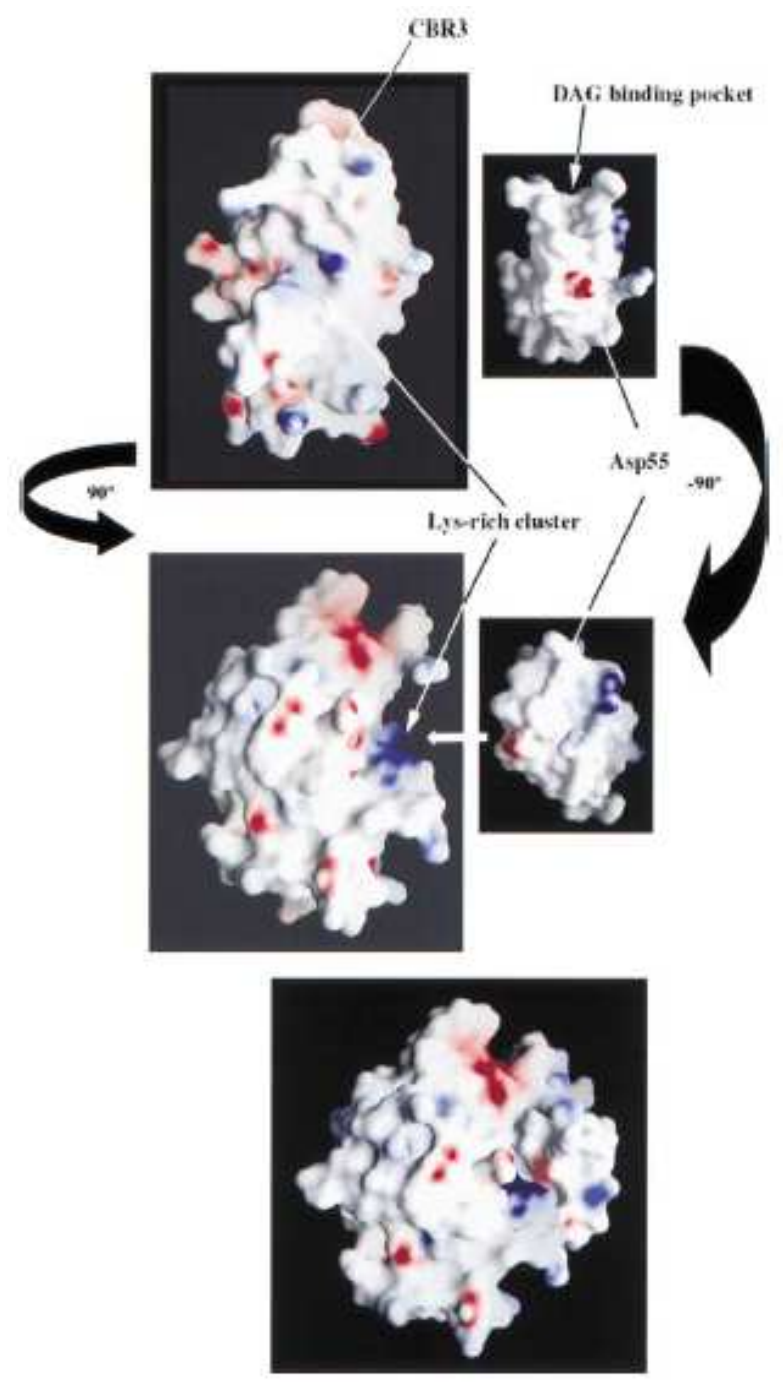

Figure 7. Two views, 908 apart from each other, of the surface representation of electrostatic potentials in the isolated (a) C1A and (b C2) domains. [42] Analysis on residue Asp55, from the C1A domain, [31] and on residues from the lysinerich cluster suggests that both domains are interacting with other parts of $\mathrm{PKC} \alpha$ in the inactive conformation at the resting state (see the text). (c) Modelling allows us to place the $\mathrm{C} 1 \mathrm{a}$ domain into the convex surface of $\mathrm{C} 2$, with Asp55 interacting with the lysine-rich cluster and the C1A surface that includes the putative DAG binding pocket making mainly hydrophobic contacts with CBR3. The DAG binding pocket and the lysine-rich cluster would both become accessible to further interactions only after the separation of the $\mathrm{C} 1 \mathrm{a}$ and $\mathrm{C} 2$ domain during the docking onto anionic membranes triggered by binding of calcium to the $\mathrm{C} 2$ domain (see the text). 


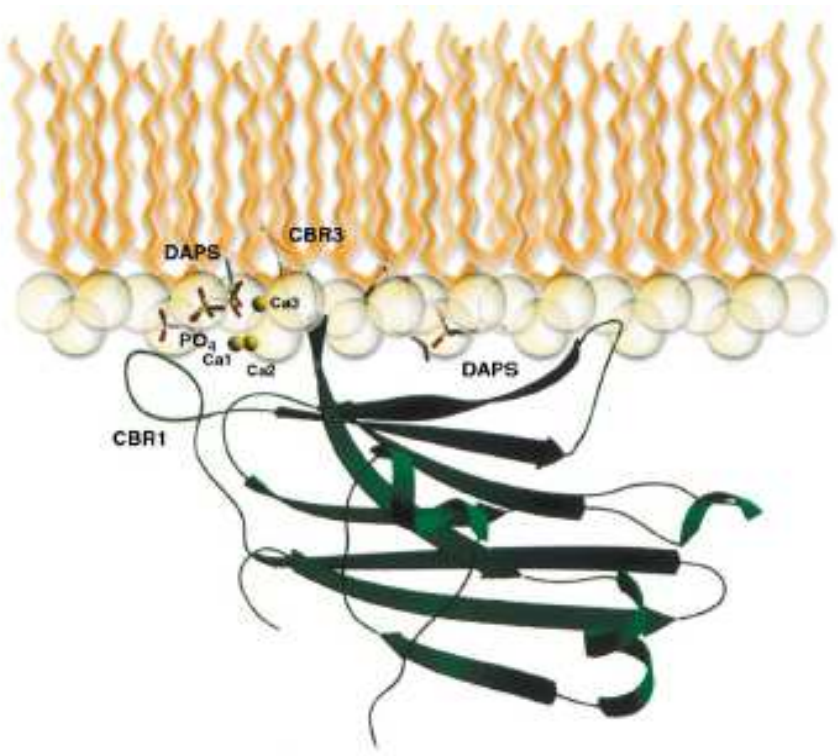

Figure 8. Docking of the complex of the PKCa-C2 domain with three calcium ions onto a model membrane. The phosphate and the head groups from the two DAPS molecules found in the structure of the DAPS complex are shown to emphasise that they could correspond to three polar heads on the surface of anionic membranes. In the resulting docked model, only the central part of CBR3 from the C2 domain is inserted into the lipid bilayer, as had been proposed from the structure of the DCPS complex. [15]

\section{Docking model}

The Ca1 ion directly coordinated to the phosphoryl moiety of DCPS and a phosphate group in the lysine-rich cluster region in the DCPS complex suggested a binding mechanism of the C2 domain to phospholipid membranes. [15] According to this mechanism, the presence of $\mathrm{Ca} 1$, and of $\mathrm{Ca} 2$, would trigger the interaction with negatively charged phospholipids at the membrane surface. This first contact would enable different protein residues located in CBR3 to interact by penetrating into the membrane. The location of the phosphate ion, at the lysine-rich cluster region, could correspond to the polar head of another phospholipid molecule interacting electrostatically with the C2 domain. [15]

The results obtained in the present study seem to confirm most of the prominent peculiarities of the proposed docking mechanism and provide deeper understanding of some critical features, in particular: (i) the explicit demonstration of a second phospholipid- binding site in the vicinity of the lysine-rich cluster region where electrostatic interactions appear to act as the dominant binding forces and that would take place upon CBR3 membrane penetration. (ii) The possible correlation between the type and the occupancy of the lipids bound to the $\mathrm{C} 2$ domain and the occupancy and stability of the third calcium ion. (iii) The possibility of a third binding site for head groups of anionic phospholipids when a third calcium ion is bound. The three phospholipid-binding sites define a structurally feasible anchorage plane on the $\mathrm{C} 2$ domain (Figure 8).

\section{Conclusions}


C2 domains are remarkable modules present in a wide variety of proteins, in particular related to membrane trafficking and signal transduction. The $\mathrm{C} 2$ domain of $\mathrm{PKC} \alpha$ is responsible for the initial $\mathrm{Ca}^{2+}$ and PS-dependent electrostatic binding of PKC $\alpha$ to anionic membranes. [22,24,29,32] The four crystallographic structures of the PKC $\alpha-C 2$ domain now available (Table 2) confirm that the number of calcium ions as well as the number of phosphate groups and phospholipid molecules bound to the domain can vary. The interplay between calcium ions and phosphate groups or phospholipid molecules in the C2 domain of PKC $\alpha$ is strongly supported by the specificity and spatial organization of the binding sites in the domain and by the variable occupancies of ligands found in the different crystal structures. These structural results, together with the wealth of biochemical and biological information available for PKCs allow us to envision an exquisite and versatile tuning of $\mathrm{PKC} \alpha$ activity at the level of the binding affinity of the $\mathrm{C} 2$ domain to membranes.

\section{Materials and Methods}

\section{Expression and purification of the PKC-C2 domain}

The PKC $\alpha-C 2$ domain, including rat PKC $\alpha$ residues from His155 to Gly293, was expressed and purified as described [15] Expression and purification of the wild-type and mutants GST-PKC $\alpha-\mathrm{C} 2$ domain was as described. [33] All the mutants were expressed as soluble proteins in Escherichia coli at levels comparable to that of the wild-type protein, which is an indication that none of the mutations produced severe conformational changes. Furthermore, residues changed in the lysine-rich cluster are exposed to the solvent with no apparent structure stabilizing roles.

\section{Phospholipid binding measurement}

Lipid vesicles were generated by mixing chloroform solutions of 1-palmitoyl-2-oleoyl-snglycero-3-phosphocholine (POPC), 1-palmitoyl-2-oleoyl-sn-glycero-3- phosphoserine (POPS) or 1palmitoyl-2-oleoyl-sn-phosphatidic acid (POPA) (Avanti Polar Lipids, Inc.) at the desired composition and dried from the organic solvent under a stream of nitrogen and then further dried under vacuum for 60 minutes. 1,2-Dipalmitoyl-L-3-phosphatidyl $N$-methyl- $\left[{ }^{3} \mathrm{H}\right]$ choline (Dupont; specific activity $56 \mathrm{Ci} / \mathrm{mmol}$ ) was included in the lipid mixture as a tracer, at approximately $3000-6000 \mathrm{cpm} / \mathrm{mg}$ of phospholipid. Dried phospholipids were resuspended in $50 \mathrm{mM}$ Hepes ( $\mathrm{pH} 7.2$ ), $0.1 \mathrm{M} \mathrm{NaCl}, 0.5 \mathrm{mM}$ EGTA by vigorous vortex mixing and subjected to direct probe sonication (three cycles of 30 seconds). The suspension was centrifuged for 20 minutes at 14,000g to remove aggregated material. A standard assay [34] contained 20 $\mathrm{mg}$ of PKC-C2 domain bound to glutathione-Sepharose beads, which were prewashed with the respective test solutions and resuspended in $0.1 \mathrm{ml}$ of $50 \mathrm{mM}$ Hepes ( $\mathrm{pH} 7.2), 0.1 \mathrm{M} \mathrm{NaCl}, 0.5 \mathrm{mM}$ EGTA containing $20 \mathrm{mg}$ of the corresponding lipids. The mixture was incubated at room temperature for 15 minutes with vigorous shaking, then centrifuged briefly in a tabletop centrifuge. The beads were washed three times with $1 \mathrm{ml}$ of the incubation buffer without liposomes. Liposome binding was then quantified by liquid scintillation counting of the radioactivity associated with the beads. 


\section{Phospholipids used in the crystallographic analysis}

1,2-Dicaproyl-sn-phosphatidic acid (DCPA) is a commercial product and was obtained from Avanti Polar Lipids, Inc. (Alabaster, AL).

1,2-Diacetyl-sn-phosphatidylserine (DAPS) was obtained as follows: L- $\alpha$ glycerophosphate di(monocyclohexylammonium) salt (Sigma) $(1 \mathrm{~g}, 2.7 \mathrm{mmol})$ was dissolved in water and the olution was passed through a Dowex $50 \mathrm{~W} \times 4$ (pyridinium form) column $(6 \mathrm{~cm} \times 3 \mathrm{~cm})$ eluted with water $(100 \mathrm{ml})$ to obtain glycerophosphate pyridinium salt. The elution was concentrated to dryness, yielding $0.65 \mathrm{~g}$ of an oily residue that was dried by evaporation of methanol and ethyl ether in a vacuum drier. The result was dissolved in $2.3 \mathrm{ml}$ of acetic anhydride. Then a drop of concentrated sulphuric acid was added and the resulting mixture was heated at $50{ }^{\circ} \mathrm{C}$ for one hour. The mixture was cooled to room temperature and 10 $\mathrm{ml}$ of a water-ice mixture was added. The resulting mixture was kept at $4{ }^{\circ} \mathrm{C}$ overnight. An oil formed, which was separated from the water and dried under vacuum, yielding $0.8 \mathrm{~g}$ of the 1,2-diacetyl-snglycerophosphate as a white foam. This compound was dissolved in $20 \mathrm{ml}$ of dry pyridine; and $0.43 \mathrm{~g}$ of t-butyloxycarbonyl (Boc)-L-serine and $2.1 \mathrm{~g}$ of $\mathrm{N}, \mathrm{N}$-dicyclohexylcarbodiimide was added. After 16 hours of stirring at room temperature, the solution was filtered to eliminate the dicyclohexylurea formed and the solution was concentrated to dryness. The residue was dissolved in water and washed with ethyl ether (three times) and dichloromethane (twice). The aqueous phase was concentrated to dryness. The residue was cooled with ice and dissolved in $5 \mathrm{ml}$ of trifluoroacetic acid (TFA). The solution was kept at room temperature for 20 minutes and $20 \mathrm{ml}$ of ethyl ether was added. A yellowish oil formed that was recovered by centrifugation, yielding $0.4 \mathrm{~g}$ of the desired product carrying pyridinium as a counter ion. Before use of this compound for crystallisation, aliquots of the product were passed over a Dowex 50W $\mathrm{x}$ 4 (sodium form) eluted with water to obtain the sodium salt. ${ }^{1} \mathrm{H}$ NMR $\delta\left(\mathrm{CD}_{3} \mathrm{OD}\right) \mathrm{ppm}: 4.2(\mathrm{~m}, 1 \mathrm{H}), 4.08$ (m, 1H), $3.92(\mathrm{~m}, 2 \mathrm{H}), 3.62(\mathrm{~m}, 2 \mathrm{H}), 1.97$ (s, 3H), 1.89 (s, 3H). EM (electrospray, negative mode): 342.92 $\left(\mathrm{M}-\mathrm{H}^{+}\right), 112.7\left(\mathrm{TFA}-\mathrm{H}^{+}\right)$expected for $\mathrm{C}_{10} \mathrm{H}_{18} \mathrm{O}_{10} \mathrm{NP} 344.18$.

\section{Crystallisation and data collection}

Solutions containing the $\mathrm{PKC} \alpha-\mathrm{C} 2$ domain at $8 \mathrm{mg} / \mathrm{ml}$ were pre-incubated overnight at $4{ }^{\circ} \mathrm{C}$ with $25 \mathrm{mM} \mathrm{CaCl}_{2}$ and $2 \mathrm{mM}$ of DCPA and DAPS, respectively. Crystals of both complexes were obtained with the hanging-drop, vapour-diffusion technique at $20{ }^{\circ} \mathrm{C}$ by mixing $1 \mu 1$ of the protein complex with an equal volume of the crystallization buffer that contained $20 \%(\mathrm{w} / \mathrm{v})$ polyethylene glycol (PEG8K) and 50 $\mathrm{mM}$ potassium phosphate $(\mathrm{pH} 6.5)$, inverted over a $1 \mathrm{ml}$ reservoir containing the crystallization buffer. Crystals from both the PKC $\alpha-C 2-\mathrm{Ca}^{2+}-$ DAPS and PKC $\alpha-C 2-\mathrm{Ca}^{2+}-\mathrm{DCPA}$ complexes appeared in three to four days and grew, for three weeks, up to $0.6 \mathrm{~mm} \times 0.1 \mathrm{~mm} \times 0.1 \mathrm{~mm}$ in size. Crystals from the two complexes were isomorphous, space group $P 3_{2} 21$, and contained one protein subunit per asymmetric unit with a solvent volume content of about $50 \%(\mathrm{v} / \mathrm{v})$. Diffraction data sets were collected at $100 \mathrm{~K}$ on a MarCCD detector using synchrotron radiation at the ESRF (Grenoble), at $1.9 \AA$ and $2.0 \AA$ resolution for the DAPS and DCPA crystal complexes, respectively. Crystals were cryo-protected by soaking for one 
minute in a solution containing the crystallisation buffer and $20 \%(\mathrm{v} / \mathrm{v})$ glycerol. Diffraction intensities were evaluated and scaled internally using the MOSFLM [35] and SCALA [36] programs from the CCP4 package (Table 1).

\section{Structure determination and refinement}

For crystals of the PKC $\alpha-C 2-\mathrm{Ca}^{2+}-\mathrm{DAPS}$ and the PKC $\alpha-\mathrm{C} 2-\mathrm{Ca}^{2+}-\mathrm{DCPA}$ complexes, the coordinates of the PKC $\alpha-C 2-\mathrm{Ca}^{2+}$ model (PDB ID code 1DSY), [15] with solvent molecules and ions omitted, were used as the starting model to determine the structure of the two complexes by molecular replacement using the AMoRe program. [37] Final models of the two complexes were obtained by iterative cycles of manual rebuilding with program $\mathrm{O}$ [38] and automatic refinement with CNS, [39] including bulk solvent correction and restrained isotropic individual $B$-factors at the final rounds of refinement. Both structures exhibit good stereochemistry, with all the residues situated inside the most favourable or the permitted regions of the Ramachandran plots (Table 1). [40] Difference and omit $\left(2 F_{o}\right.$ $\left.F_{c}\right)$ and $\left(F_{o}-F_{c}\right)$ electron density maps for the DAPS complex indicated the presence of three calcium ions at the top of the b-sandwich at the putative $\mathrm{Ca}^{2+}$-binding site. Two of the calcium ions coincided with $\mathrm{Ca} 1$ and $\mathrm{Ca} 2$, as defined in the structure of the PKC $\alpha-\mathrm{Ca}^{2+}-\mathrm{DCPS}$ complex, [15] while the third was found in a location equivalent to site IV, as defined in the structure of PKC $\beta$-C2. [14] Electron density indicated the presence of a DAPS molecule in close contact with Ca1 and of a phosphate ion in the vicinity of Ca3. Finally, well-defined electron density near the lysine-rich cluster from strands ( $\beta 3$ and ( $\beta 4$ was interpreted as a second DAPS molecule. In the DCPA complex, electron density confirmed the presence of calcium ions $\mathrm{Ca} 1$ and $\mathrm{Ca} 2$, but was weaker at the location for $\mathrm{Ca} 3$, which could be interpreted either as a well-defined water molecule or as a $\mathrm{Ca}^{2+}$ with low occupancy. Non-protein electron density in the vicinity of Cal was assigned to a DAPS molecule, though only the region for the phosphate group was well defined. Finally, electron density near the lysine-rich cluster, again clearly visible in the DCPA complex, was interpreted as corresponding to the phosphoryl and glycerol head groups of the phospholipid molecule.

\section{Deposition of coordinates}

Coordinates of the ternary complexes of PKC $\alpha-\mathrm{Ca}^{2+}$ with both DAPS and DCPA, reported in this study, will be deposited in the Protein Data Bank and are available directly from the authors on request until they are processed and released.

\section{Acknowledgments}

This research was supported by grants PB98-0389 to the Universidad de Murcia, and BIO0990865 to the IBMB and by 1FD97-1558 from DGESIC (Spain) to a collaborative project between the Universidad de Murcia and the IBMB. Data were collected at the EMBL protein crystallography beam lines at ESRF (Grenoble) within a Block Allocation Group (BAG Barcelona), as at ESRF BM14. This 
work was supported financially by the ESRF and by grant HPRI-CT-1999-00022 of the European Union. We specially thank the ESRF local contacts and the team of the Spanish CRG beam line BM14 for providing assistance and support for measurements.

\section{References}

1. Dekker, L. V. \& Parker, P. J. (1994). Protein kinase C- a question of specificity. Trends Biochem. Sci. 19, 73-77.

2. Newton, A. \& Johnson, J. E. (1998). Protein kinase C: a paradigm for regulation of protein function by two membrane-targeting modules. Biochim. Biophys. Acta, 1376, 155-172.

3. Lee, M. H. \& Bell, R. M. (1986). The lipid binding regulatory domain of protein kinase C: a $32 \mathrm{kDa}$ fragment contains calcium and phosphatidyl serine dependent phorbol diester binding activity. J. Biol. Chem. 261, 14867-14870.

4. Boni, L. T. \& Rando, R. R. (1985). The nature of protein kinase C activation by physically defined phospholipid vesicles and diacylglycerols. J. Biol. Chem. 260, 10819-10825.

5. Lee, M.-H. \& Bell, R. M. (1989). Phospholipid functional groups involved in protein kinase C activation, phorbol ester binding, and binding to mixed micelles. J. Biol. Chem. 264, 14797-14805.

6. Newton, A. C. \& Keranen, L. M. (1994). Phosphatidyl-L-serine is necessary for protein kinase C's high affinity interaction with diacylglycerol-containing membranes. Biochemistry, 33, 6651-6658.

7. Johnson, J. E., Zimmerman, M. L., Daleke, D. L. \& Newton, A. C. (1998). Lipid structure and not membrane structure is the major determinant in the regulation of protein kinase $\mathrm{C}$ by phosphatidylserine.

Biochemistry, 37, 12020-12025.

8. Nalefski, E. A. \& Falke, J. J. (1996). The C2 domain calcium-binding motif: structural and functional diversity. Protein Sci. 5, 2375-2390.

9. Rizo, J. \& Südhof, T. C. (1998). C2-domains, structure and function of a universal $\mathrm{Ca}^{2+}$-binding domain. J. Biol. Chem. 273, 15879-15882.

10. Sutton, R. B., Davletov, B. A., Berghuis, A. M., Südhof, T. C. \& Sprang, S. R. (1995). Structure of the first C2 domain of synaptotagmin I: a novel calcium/ phospholipid-binding fold. Cell, 80, 929-938.

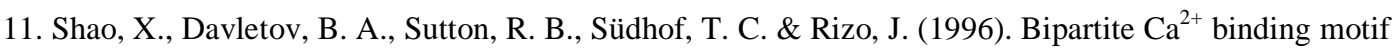
in C2 domains of synaptotagmin and PKC. Science, 273, 248-251.

12. Essen, L.-O., Perisic, O., Lynch, D. E., Katan, M. \& Williams, R. L. (1997). A ternary metal binding site in the C2 domain of phosphoinositide-specific phospholipase C-delta1. Biochemistry, 36, 27532762.

13. Perisic, O., Fong, S., Lynch, D. E., Bycroft, M. \& Williams, R. L. (1998). Crystal structure of a calcium- phospholipid binding domain from cytosolic phospholipase A2. J. Biol. Chem. 273, 1596-1604.

14. Sutton, R. B. \& Sprang, S. R. (1998). Structure of the protein kinase C $\beta$ phospholipid-binding C2 domain complexed with $\mathrm{Ca}^{2+}$. Structure, 6, 1395-1405.

15. Verdaguer, N., Corbalan-Garcia, S., Ochoa, W. F., Fita, I. \& Gómez-Fernández, J. C. (1999). Ca ${ }^{2+}$ bridges the $\mathrm{C} 2$ membrane-binding domain of protein kinase $\mathrm{C}_{\text {alpha }}$ directly to phosphatidylserine. $\mathrm{EMBO}$ J. 18, 6329-6338. 
16. Ubach, J., Zhang, X., Shao, X., Südhof, T. C. \& Rizo, J. (1998). Ca ${ }^{2+}$ binding to synaptotagmin: how many Ca2p ions bind to the tip of a C2-domain? EMBO J. 17, 3921-3930.

17. Fernández-Chacón, R., Königstorfer, A., Gerber, S. H., García, J., Matos, M. F., Stevens, C. F. et al. (2001). Synaptotagmin I functions as a calcium regulator of release probability. Nature, 410, 41-49.

18. Davletov, B. A. \& Südhof, T. C. (1993). A single C2 domain from synaptotagmin I is sufficient for high affinity $\mathrm{Ca}^{2+}$ /phospholipid binding. J. Biol. Chem. 268, 26386-26390.

19. Li, C., Ullrich, B., Zhang, J. Z., Anderson, R. G. W., Brose, N. \& Südhof, T. C. (1995). Ca ${ }^{2+}$ dependent and independent activities of neural and non neural synaptograms. Nature, 375, 594-599.

20. Nalefski, E. A., Slazas, M. M. \& Falke, J. J. (1997). Calcium signalling cycle of a membrane-docking C2 domain. Biochemistry, 36, 12011-12018.

21. Zhang, X., Rizo, J. \& Südhof, T. C. (1998). Mechanism of phospholipid binding by the C2A-domain of synaptotagmin I. Biochemistry, 37, 12395-12403.

22. Conesa-Zamora, P., Gomez-Fernandez, J. C. \& Corbalan-Garcia, S. (2000). The C2 domain of PKC $\alpha$ is directly involved in the DAG-dependent binding of the $\mathrm{C} 1$ domain to the membrane. Biochim. Biophys. Acta, 1487, 246-254.

23. Conesa-Zamora, P., Lopez-Andreo, M. J., Gómez- Fernández, J. C. \& Corbalán-García, S. (2001). Identification of the phosphatidylserine binding site in the $\mathrm{C} 2$ domain that is important for $\mathrm{PKC} \alpha$ activation and in vivo cell localization. Biochemistry, 40, 13898-13905.

24. Medkova, M. \& Cho, W. (1998). Mutagenesis of the C2 domain of protein kinase C $\alpha$. J. Biol. Chem. 273, 17544-17552.

25. Bittova, L., Sumadea, M. \& Cho, W. (1999). A structure- function study of the C2 domain of cytosolic phospholipase A2. J. Biol. Chem. 274, 9665-9672.

26. Mosior, M. \& Newton, A. C. (1998). Mechanism of the apparent cooperativity in the interaction of protein kinase $\mathrm{C}$ with phosphatidylserine. Biochemistry, 37, 17271-17279.

27. Nalefski, E. A. \& Newton, A. C. (2001). Membrane binding kinetics of protein kinase C $\beta$ II mediated by the C2 domain. Biochemistry, 40, 13216-13229.

28. Igarashi, K., Kaneda, M., Yamaji, A., Saido, T. C., Kikkawa, U., Ono, U., Inoue, K. \& Umeda, M. (1995). A novel phosphatidylserine-binding peptide motif defined by an anti-idiotypic monoclonal antibody. Localization of phosphatidylserine-specific binding sites on protein kinase $\mathrm{C}$ and phosphatidylserine decarboxylase. J. Biol. Chem. 270, 29075-29078.

29. Edwards, A. S. \& Newton, A. C. (1997). Regulation of protein kinase C $\beta$ II by its C2 domain. Biochemistry, 36, 15615-15623.

30. Johnson, J. E., Edwards, A. S. \& Newton, A. C. (1997). A putative phosphatidylserine binding motif is not involved in the lipid regulation of protein kinase C. J. Biol. Chem. 272, 30787-30792.

31. Bittova, L., Stahelin, R. V. \& Cho, W. (2001). Roles of ionic residues of the C1 domain in protein kinase C- $\alpha$. Activation and the origin of phosphatidylserine specificity. J. Biol. Chem. 276, 4218-4226.

32. Oancea, E. \& Meyer, T. (1998). Protein kinase C as a molecular machine for decoding calcium and diacylglycerol signals. Cell, 95, 307-318. 
33. Corbalan-Garcia, S., Rodriguez-Alfaro, J. A. \& Gomez-Fernandez, J. C. (1999). Determination of the calcium-binding sites of the $\mathrm{C} 2$ domain of $\mathrm{PKC} \alpha$ that are critical for its translocation to the plasma membrane. Biochem. J. 337, 513-521.

34. Davletov, B. A. \& Südhof, T. C. (1993). A single C2 domain from synaptotagmin I is sufficient for high affinity $\mathrm{Ca}^{2+}$ /phospholipid binding. J. Biol. Chem. 268, 26386-26390.

35. Leslie, A. G. W. (1992). Recent changes to the MOSFLM package for processing film and image plate data. CCP4 and ESF-EACMB Newsletters on Protein Crystallography, no. 26, SERC Daresbury Laboratory, Warrington, UK.

36. Evans, P. R. (1997). Scala. Joint CCP4 ESF-EACBM Newsletter, 33, 22-24.

37. Navaza, J. (1994). AMoRe: an automated package for molecular replacement. Acta Crystallog. sect. A, 50, 157-163.

38. Jones, T. A., Zou, J. Y., Cowan, S. W. \& Kjeldgaard, M. (1991). Improved methods for building protein models in electron density maps and the location of errors in these models. Acta Crystallog. sect. A, 47, 110-119.

39. Brünger, A. T., Adams, P. D., Clore, G. M., DeLano, W. L., Gros, P., Grosse-kunstleve, R. W. et al. (1998). Crystallography and NMR system (CNS): a new software suite for macromolecular structure determination. Acta Crystallog. sect. D, 54, 157-167.

40. Laskowski, R. A., Mac Arthur, M. W., Moss, D. S. \& Thornton, J. M. (1993). PROCHECK: a program to check the stereochemical quality of protein structures. J. Appl. Crystallog. 26, 283-291.

41. Wallace, A. C., Laskowski, R. A. \& Thornton, J. M. (1995). LIGPLOT: a program to generate schematic diagrams of protein-ligand interactions. Protein Eng. 8, 127-134.

42. Nicholls, A., Sharp, K. \& Honig, B. (1991). GRASP, graphical representation and analysis of structural properties of proteins. Proteins: Struct. Funct. Genet. 11, 281-296. 